\title{
New Modified 256-bit MD5 Algorithm with SHA Compression Function
}

\author{
Alok kumar kasgar \\ School of IT \\ Rajiv Gandhi Technical University \\ Bhopal (M.P.)
}

\author{
Jitendra Agrawal \\ School of IT \\ Rajiv Gandhi Technical University \\ Bhopal (M.P.)
}

\author{
Santosh Sahu \\ School of IT \\ Rajiv Gandhi Technical University \\ Bhopal (M.P.)
}

\begin{abstract}
In the past few years, there have been significant research advances in the analysis of hash functions and it was shown that none of the hash algorithm is secure enough for critical purposes whether it is MD5 or SHA-1. Nowadays scientists have found weaknesses in a number of hash functions, including MD5, SHA and RIPEMD so the purpose of this paper is combination of some function to reinforce these functions and also increasing hash code length upto 256 that makes stronger algorithm against collision attests.
\end{abstract}

\section{Key Words}

MD Algorithm; Hash Function; compressed function and Hash code length.

\section{INTRODUCTION}

Hash functions are one-way functions with as input a string of arbitrary length (the message) and as output a fixed length strings (the hash value). The hash value is a kind of signature for that message. One-way functions work in one direction, meaning that it is easy to compute the hash value from a given message and hard to compute a message that hashes to a given hash value.

A hash collision is a pair of different messages $\mathrm{m} 16=\mathrm{m} 2$ having the same hash value $\mathrm{H}(\mathrm{m} 1)=\mathrm{H}(\mathrm{m} 2)$. Therefore second pre-image resistance and collision resistance are also known as weak and strong collision resistance, respectively. Since the domain of a hash function is much larger (can even be infinite) than its range, it follows from the pigeonhole principle that many collisions must exist. A brute force attack can find a pre-image or second pre-image for a general hash function with $\mathrm{n}$-bit hashes in approximately $2 \mathrm{n}$ hash operations. Because of the birthday paradox a brute force approach to generate collisions will succeed in approximately $2(n / 2)$ hash operations. Any attack that requires less hash operations than the brute force attack is formally considered a break of a cryptographically hash function [1].

MD stands for 'Message Digest' and describes a mathematical function that can take place on a variable length string. The number 5 simply depicts that MD5 was the successor to MD4. MD5 is essentially a checksum that is used to validate the authenticity of a file or a string and this is one of its most common uses. Let's take a look at a working example. Let's say you have released some software or a program that you want people to freely distribute, this is all good and well but what if someone was to tamper with your application with malicious intent? For example what if they added malware onto your program, how would people know? Well if you had taken an MD5 checksum of your original program and made this information public, then when people downloaded your software could then check their downloaded file and check that the MD5 checksum matches yours. If it does then great! If not then it means your program has been tampered with. MD5, with the full name of the Message-digest Algorithm 5, is the fifth generation on behalf of the message digest algorithm. In August 1992, Ronald L.Rivest submitted a document to the IETF (The Internet Engineering Task Force) entitled "The MD5Message-Digest Algorithm", which describes the theory of this algorithm. For the publicity and security of algorithm, it has been widely used to verify data integrity in a variety of program languages since the 1990s.MD5 was developed from MD, MD2, MD3 and MD4. It can compress any length of data into an information digest of $128 \mathrm{bits}$ while this segment message digest often claims to be a digital fingerprint of the data. This algorithm makes use of a series of non-linear algorithm to do the circular operation, so that crackers cannot restore the original data. In cryptography, it is said that such algorithm as an irreversible algorithm, can effectively prevent data leakage caused by inverse operation. Both the theory and practice have good security, because the use of MD5 algorithm does not require the payment of any royalties, time, and cost less which make it be widely used in the general non-top-secret applications. But even the top-secret area, MD5 may well be an excellent Intermediate technology [2].

SHA (Secure Hash Algorithm) is a 160-bit hash function published in 1993 as the Secure Hash Standard by NIST (The National Institute of Standards and Technology) [3]. It is based on MD5 and is mainly used in digital signature schemes. It hashes onto 160 bits and uses the MerkleDamgard construction from a $160 \times 512 \rightarrow 160$ compression function. As for MD5, the compression functions of SHA and SHA-1 are made from an "encryption function" by the Davies-Meyer scheme.

A 160-bit hash function has a security level on the order of 80 bits, so SHA-1 is designed to match the security level that uses an 80-bit secret key [1]. SHA-0 analyzed by Chabaud and Joux using differential methods (local collisions and disturbance vectors) and they found a collision attack on SHA-0 of complexity 261 [4]. Biham and Chen found near collisions on SHA-0 in complexity 240 [5]. The work of Biham, Joux, and Chen included the first real collision of SHA-0 [5] therefore; the migration to more secure hash functions should be accelerated. In 2001, NIST developed three new hash functions SHA-256, 384, and 512 whose hash value sizes are 256,384 , and 512 bits, respectively. These hash functions are standardized with SHA-1 as SHS (Secure Hash Standard) [6, 7], and a 224-bit hash function, SHA-224, based on SHA-256, was added to SHS in 2004 but moving to other members of the SHA family may not be a good long term solution [8].

\section{EXISTING HASH ALGOTITHM LIMITATION}

In the past few years, there have been significant research advances in the analysis of hash functions and it was shown that none of the hash algorithm is secure enough for critical purposes. As mentioned before SHA- 0 changed to SHA- 1 because SHA-0 differential paths had a problem (i.e. $\Delta \mathrm{A}, \Delta \mathrm{B}$, 
$\Delta \mathrm{C}, \Delta \mathrm{D}, \Delta \mathrm{E}=0$ ) in the middle of calculation and collision will find easily as shown in Table3. Although SHA-1 tried to remove this flaw but the weakness still remained $[9,10]$. In fact differential cryptanalysis works when the attacker can predict the evolution of differences with a high probability because of existence of Neutral Bits. It is easy to cancel a difference in the state by changing compress functions before starting next round or by creating another difference in the messages that is prepared in our algorithm but it is obvious that they should change by a procedure to keep the solidarity regarding to Merkle-Damgard theory which proved that if the compression function is collision-resistant, then the hash function is collision resistant as well and mathematical induction need solidarity [1].

The weakness in SHA family originated from this fact that possibility of two different input value will produce the same output value in the middle of algorithm and it is important to have a good diffusion so that the output in each round will be spread out and not to be equal with the same output in the next coming stages. This has done with XOR-ing each stage output with next input something that has already done in $\mathrm{CBC} / \mathrm{MAC}$ then the difference of outputs will be ensured but the previous digest algorithms does not use this technique. At the same time Double-Davies-Meyer scheme will ensure the diffusion and will resist against hackers to reach the minimum distance. In this stage it is shown how it is possible to combine two methods to have a good result with multiple security level that has been discussed before.

MD5 is a famous cryptographic hash function example. It is widely used in Internet applications. It was published as the RFC-1321 Internet standard in 1992 [2]. It hashes arbitrary length bit strings onto 128 bits and uses the Merkle-Damgard construction from a $128 \times 512 \rightarrow 128$ compression function. The compression function is made from an "encryption function" by the Davies-Meyer scheme and will map a 128bit value $\mathrm{H}=(\mathrm{A}, \mathrm{B}, \mathrm{C}, \mathrm{D})$ and a 512-bit key block $\mathrm{B}$ into a 128 -bit value. Actually 128-bit hash value is not adequately long to stop birthday attacks and two messages that have the same hash value could be found easily so MD5 is no longer secure, and it is not recommended for use in the future [17].

\section{MODIFIED MD5 ALGORITHM}

MD5algorithm is co-invented by Rivets in MIT Computer Science Laboratory and RSA Data Security Company. MD5 is a non-reversible encryption algorithm [3]. It is widely applied in many aspects, including digital signature, encryption of information in a database and encryption of communication information. It makes large amounts of information to be compressed into a confidential format before signing the private key by digital signature soft (that is, any length byte string is transformed into a certain length of big integer).A brief description of new modified MD5 algorithm as follows: MD5algorithm divides plaintext input into blocks each which has512-bit, and each block is again divided into sixteen 32-bitmessage words, after a series of processing, the outputs of the algorithm consist of eight 32-bit message words. After these eight 32-bit message words are cascaded, the algorithm generates a 128-bit hash value which is the required cipher text. Specific steps are as follows [11, 12, 13]:

\subsection{Padding-bit}

Without loss of generality, supposes that the original data at the source has $\mathrm{k}$ bits (mk-1, mk-2...m0), where mi_ $\{0,1\}$. For MD5 algorithm, its $\mathrm{k}$ bits data must be processed in 512bit message block, so if the length of source is less than that length, padding is always added until its length in bits is congruent to 448 modulo 512 (length $=448 \bmod 512$ ). The padding consists of a single 1-bit followed by the necessary number of 0-bits.

\subsection{Padding the length of data}

A 64-bit representation of the length on bits of the original message is appended to the result of above step. It is present by two 32bitdigits. At this time, the length of message is filled to a multiple of 512 .

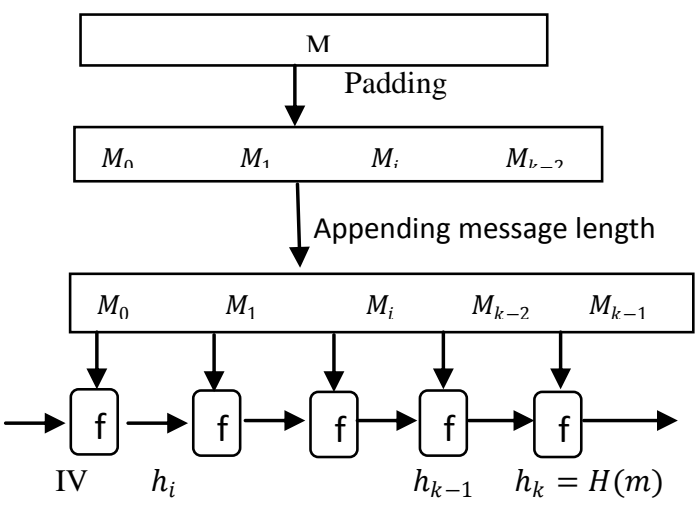

Figure 1: Working principle of an iterated hash function

\subsection{Initialize MD5 Standard parameters}

Eight 32-bit integers A, B,C,D,E,F,G,H are called chaining variables, used to calculate the message digest, are initialized by hexadecimal number

$\mathrm{A}=0 \times 01234567$

$\mathrm{B}=0 \mathrm{x} 89 \mathrm{abcdef}$

$\mathrm{C}=0 \mathrm{xfedcba98}$

$\mathrm{D}=0 \times 76543210$

$\mathrm{E}=0 \times 12 \mathrm{ac} 2375$

$\mathrm{F}=0 \times 3 \mathrm{~b} 341042$

$\mathrm{G}=0 \times 5 \mathrm{f} 62 \mathrm{~b} 97 \mathrm{c}$

$\mathrm{H}=0 \mathrm{x} 4 \mathrm{ba} 763 \mathrm{ed}$

\subsection{Bit operation functions}

We define eight bit operation functions $\mathrm{J}, \mathrm{K}, \mathrm{L}, \mathrm{M}, \mathrm{N}, \mathrm{O}, \mathrm{P}$ and $\mathrm{Q}$ respectively, in which $\mathrm{x}, \mathrm{y}, \mathrm{z}$ are three 32-bit integers. The operation is as follows:

$$
\begin{aligned}
& \mathrm{J}(\mathrm{x}, \mathrm{y}, \mathrm{z})=(\mathrm{x} \wedge \mathrm{y}) \vee((\neg \mathrm{x}) \wedge \mathrm{z}) \ldots \ldots \ldots \ldots \ldots . .1 \\
& \mathrm{~K}(\mathrm{x}, \mathrm{y}, \mathrm{z})=(\mathrm{x} \wedge \mathrm{z}) \vee(\mathrm{y} \wedge(\neg \mathrm{z})) \ldots \ldots \ldots \ldots \ldots . .2 \\
& \mathrm{~L}(\mathrm{x}, \mathrm{y}, \mathrm{z})=\mathrm{x}^{\oplus} \mathrm{y} \oplus \mathrm{z} \ldots \ldots \ldots \ldots \ldots \ldots \ldots \ldots \ldots . \ldots \ldots \\
& \mathrm{M}(\mathrm{x}, \mathrm{y}, \mathrm{z})=\mathrm{y} \oplus(\mathrm{x} \vee(\neg \mathrm{z})) \ldots \ldots \ldots \ldots \ldots \ldots . . . . . \ldots \\
& \mathrm{N}(\mathrm{x}, \mathrm{y}, \mathrm{z})=(\mathrm{x} \wedge \mathrm{y}) \bigvee((\neg \mathrm{x}) \wedge \mathrm{z}) \ldots \ldots \ldots \ldots \ldots . .5
\end{aligned}
$$

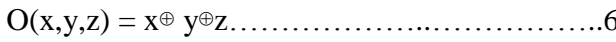

$$
\begin{aligned}
& \mathrm{P}(\mathrm{x}, \mathrm{y}, \mathrm{z})=(\mathrm{x} \wedge \mathrm{y}) \oplus(\mathrm{y} \wedge \mathrm{z}) \vee(\mathrm{z} \wedge \mathrm{x}) \ldots \ldots \ldots \ldots . . .7
\end{aligned}
$$

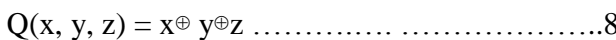

In eight functions, if the corresponding bits of $\mathrm{x}, \mathrm{y}$ and $\mathrm{z}$ are independent and uniform, then each bit of the results should be independent and uniform as well. For

$$
x=\sum_{i=1}^{32} x_{i} 2^{i-1} \in Z /\left(2^{32}\right), x^{i} \in\{0,1\}
$$

We call $x^{i}$ the i-th bit of $\mathrm{x}$. 


\subsection{Main transformation process}

The number of main looping this algorithm is the number of 512-bit information groups. The main loop have eight rounds, each round carries out 64 operations, 32 operation for first four compression function and 32 bit for next four, so the total of operations are 256 steps. The above eight chaining variables are assigned to another eight chaining values: $\mathrm{a} 0=\mathrm{A}$, $\mathrm{b} 0=\mathrm{B}, \mathrm{c} 0=\mathrm{C}, \mathrm{d} 0=\mathrm{D}, \mathrm{e} 0=\mathrm{E}, \mathrm{f} 0=\mathrm{F}, \mathrm{g} 0=\mathrm{G}, \mathrm{h} 0=\mathrm{H}$. One of the chaining values is updated in each step and computation is continued in sequence. Here we have defined eight rounds composite functions of main loop $\mathrm{nFF}, \mathrm{FF}, \mathrm{nGG}, \mathrm{GG}, \mathrm{nHH}$, $\mathrm{HH}$, nII and II respectively, which change from $\mathrm{nF}, \mathrm{F}, \mathrm{nG}, \mathrm{G}$, $\mathrm{nH}, \mathrm{H}, \mathrm{nI}$ and I. the operation is as follows:

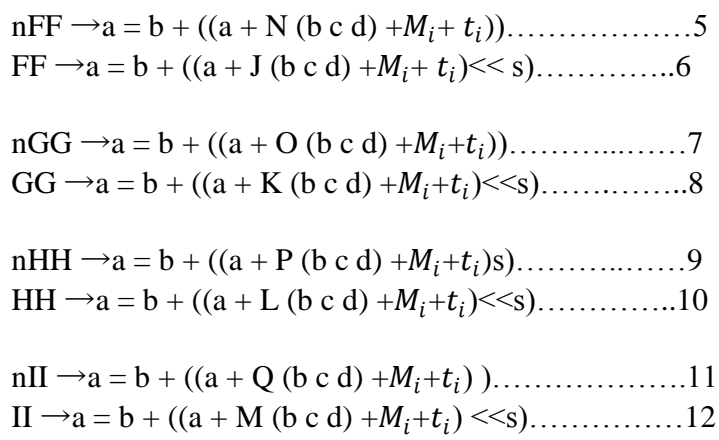

Where, + is addition modulo $2^{32}$, Mi (0_i_15) is a 32-bit message word and the 512-bit message block is divided into 16 32-bit message words. $x_{-} s$ is the left shift rotation of $x$ by $\mathrm{s}$ bits. The ti and s are step-dependent constants, ti has the following options: in i-th step, ti is the integer part of $4294967296 \times$ abs $(\sin (i)), 4294967296=2^{32}$.

After all of these steps, A, B, C, D, E, F, G, H add a, b, c, d, e, $\mathrm{f}, \mathrm{g}, \mathrm{h}$ Respectively, then the algorithm is continued to run the next 512-bit message block, the final output is A, B, C, D, E, F, G, H of cascading. Application of MD5 algorithm is to generate a message digest of information in order to prevent tampering. The result of some strings are showing in table 2 . We view the entire file as a large text message, and result in a unique message digest by the irreversible string transform method. In the future, if the contents of file are changed, we only recalculate message digest of this file, and will find the difference from the original message digest. There by, we can sure the checked file is incorrect.[14]

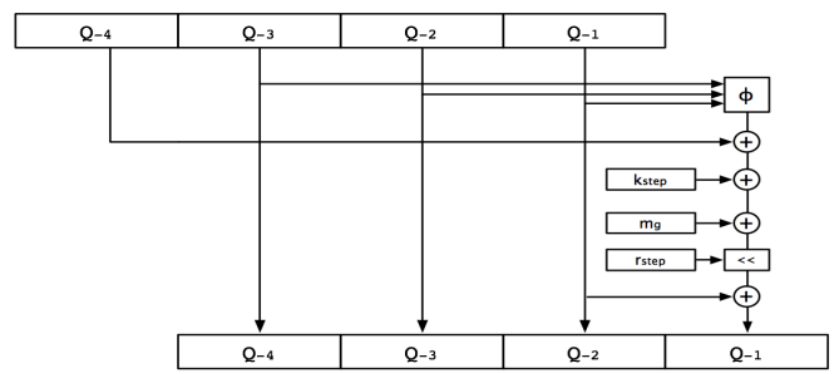

Figure 2: Standard step of compression function in MD5

\section{COLLISIONS AND PRIIMAGES}

Like every cryptographic function, hashes are susceptible to brute-force attacks. The longer $\mathrm{L}$ is, the more work an attacker has to do to mount an attack; however, hashes with longer $\mathrm{L}$ also are usually slower to computer. There are three important attacks on hashes
4.1 A "collision attack" allows an attacker to find two messages M1 and M2 that have the same hash value in fewer than $2^{\wedge}(\mathrm{L} / 2)$ attempts.

4.2 A "first-preimage attack" allows an attacker who knows a desired hash value to find a message that results in that value in fewer than $2^{\wedge} \mathrm{L}$ attempts.

4.3 A "second-preimage attack" allows an attacker who has a desired message M1 to find another message M2 that has the same hash value in fewer than $2^{\wedge} \mathrm{L}$ attempts.

\section{OTHER ATTECK}

\subsection{Brute force attack:}

In cryptography, a brute force attack or exhaustive key search is a strategy that can in theory be used against any encrypted data[15] by an attacker who is unable to take advantage of any weakness in an encryption system that would otherwise make his/her task easier. It involves systematically checking all possible keys until the correct key is found. In the worst case, this would involve traversing the entire search space.

\subsection{Rainbow tables}

A rainbow table is a precomputed table for reversing cryptographic hash functions, usually for cracking password hashes. Tables are usually used in recovering the plaintext password, up to a certain length consisting of a limited set of characters. It is a form of time-memory tradeoff, using less CPU at the cost of more storage. Proper key derivation functions employ salt to make this attack infeasible. Rainbow tables are a refinement of an earlier, simpler algorithm by Martin Hellman[16] that used the inversion of hashes by looking up recomputed hash chains

Table 1 Combinations Time

Symmetric key length vs brute force combinations

\begin{tabular}{|l|l|l|}
\hline $\begin{array}{l}\text { Key } \\
\text { size in } \\
\text { bits[2] }\end{array}$ & $\begin{array}{l}\text { Permu } \\
\text { tations }\end{array}$ & $\begin{array}{l}\text { Brute force time for a device } \\
\text { checking 256 permutations per second }\end{array}$ \\
\hline 8 & 28 & 0 milliseconds \\
\hline 40 & 240 & 0.015 milliseconds \\
\hline 56 & 256 & 1 second \\
\hline 64 & 264 & 4 minutes 16 seconds \\
\hline 128 & 2128 & $149,745,258,842,898$ years \\
\hline 256 & 2256 & $\begin{array}{l}50,955,671,114,250,100,000,000,000,000 \\
, 000,000,000,000,000,000,000,000 \text { years }\end{array}$ \\
\hline
\end{tabular}

\subsection{Birthday attack}

A Birth day attack is a name used to refer to a class of bruteforce attacks. It gets its name from the surprising result that the probability that two or more people in a group of 23 share the same birthday is greater than $1 / 2$; such a result is called a birthday paradox. If some function, when supplied with a random input, returns one of $\mathrm{k}$ equally-likely values, then by repeatedly evaluating the function for different inputs, we expect to obtain the same output after about $1.2 \mathrm{k} 1 / 2$. For the above birthday paradox, replace $\mathrm{k}$ with 365 . Birthday attacks are often used to find collisions of hash functions

\section{RESULTS AND DISCUSSIONS}

All the attacks of Joux et al., Biham \& Chen, and Wang et al. are differential and they use this fact that by changing a small number of message bits, it is possible to cancel the difference after a few rounds, or keep the Hamming distance low. Differences are usually defined as the XOR of the value in 
one run and the corresponding value in the other run (or alternatively additive or multiplicative difference).

We have presented a new hash function based on DoubleDavies-Meyer that satisfied Merkle-Damgard condition. Security of this new algorithm is higher than SHA-1 and MD5 because even if local collision happened in the middle of SHA second algorithm will fade it with an acceptable diffusion so at the start of next round there are no equal states with previous round. It means that $\mathrm{Hi}-\mathrm{Hi}-1 \neq 0 \mathrm{We}$ chose some messages that has already shown ascollision in MD5 and SHA-1 and changed them by XOR and Addition but we did not find any collision.

Sophisticated message modification techniques were applied to achieve the necessary conditions on the chaining variables and the message bits. The differential path for the improved algorithm is different from the previous differential path so it is resistant against local collision and differential attack.

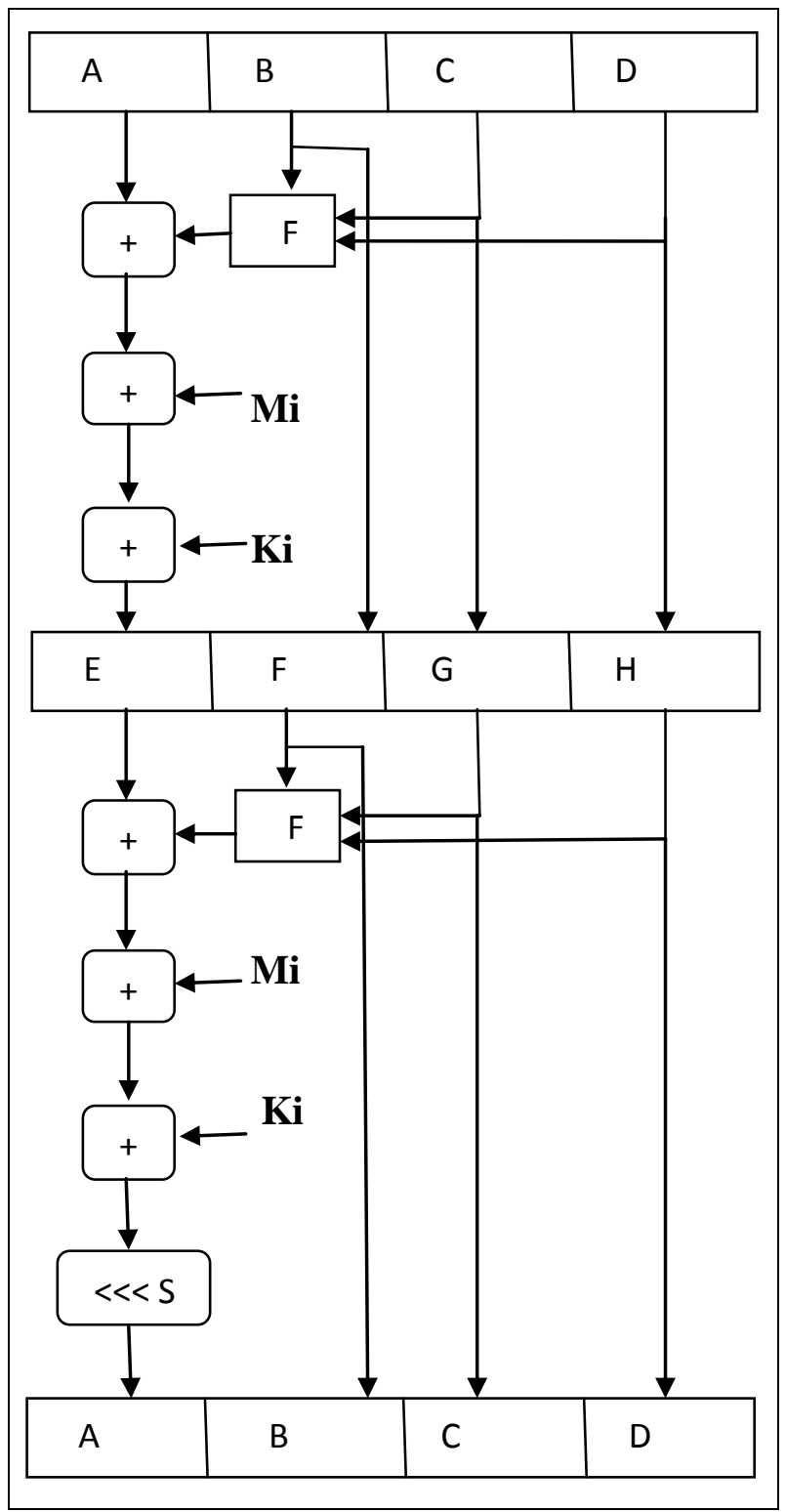

Fig.3 Diagram of the algorithm

In this scheme brute force attack takes 256 Permutations to break algorithm which takes more time than 160 bit hash function as show in the Table1. Even the last scheme is 160 bits and need 280 bit for birthday paradox but it is strong enough to the first and second preimage attack. We can extend the length of hash to 512 or 640 to be more resistible against birthday attack which comparing with its ancestors, it is more powerful.

Table. 2 Result Table

\begin{tabular}{|c|c|c|c|c|}
\hline $\begin{array}{l}\text { Messa } \\
\text { ge }\end{array}$ & $\begin{array}{l}\text { MD5 } \\
\text { (128b } \\
\text { its } \\
\text { ) }\end{array}$ & $\begin{array}{l}\text { SHA-1 } \\
\text { (160b } \\
\text { its } \\
\text { ) }\end{array}$ & $\begin{array}{l}\text { SHA *MD } \\
5 \\
(160 \mathrm{bi} \\
\text { ts ) }\end{array}$ & $\begin{array}{l}\text { SHA*MD } \\
5 \\
(256 \mathrm{bi} \\
\text { ts })\end{array}$ \\
\hline "'" & $\begin{array}{l}\text { D41D8C } \\
\text { D9 } \\
8 F 00 B 20 \\
4 \\
\text { E980099 } \\
8 \\
\text { ECF8427 } \\
\text { E }\end{array}$ & $\begin{array}{l}\text { DA39A3 } \\
\text { EE } \\
\text { 5E6B4B0 } \\
\text { D } \\
\text { 3255BFE } \\
\text { F } \\
9560189 \\
0 \\
\text { AFD807 } \\
09\end{array}$ & $\begin{array}{l}25 \mathrm{~A} 12 \mathrm{C} 0 \mathrm{~F} \\
20 \mathrm{~F} 9 \mathrm{CA} 9 \\
\text { E } \\
\text { A78B1A9 } \\
2 \\
\text { FCE44ED } \\
2 \\
88 \mathrm{C} 903 \mathrm{D} 0\end{array}$ & $\begin{array}{l}818872 \\
413013 \\
\mathrm{~d} 2 \mathrm{cfb} 8 \\
9 \mathrm{c} 56 \mathrm{a} 2 \\
8977 \mathrm{~d} 2 \\
37 \mathrm{~d} 0 \mathrm{f0} \\
\text { f41a3c } \\
4 \mathrm{afde} 4 \\
\text { f83480 } \\
\text { a0f902669 } \\
5\end{array}$ \\
\hline "a" & $\begin{array}{l}0 \mathrm{CC} 175 \\
\text { B9 } \\
\text { C0F1B6 } \\
\text { A8 } \\
31 \mathrm{C} 399 \mathrm{E} \\
2 \\
6977266 \\
1\end{array}$ & $\begin{array}{l}86 \text { F7E43 } \\
7 \\
\text { FAA5A7 } \\
\text { FC } \\
\text { E15D1D } \\
\text { DC } \\
\text { B9EAEA } \\
\text { EA } \\
377667 B \\
8 \\
\end{array}$ & $\begin{array}{l}\text { FE0173D2 } \\
6 \text { 666A447 } \\
\text { BFBB651 } \\
1 \\
\text { 4ADEA4E } \\
\text { D } \\
408 C 1925\end{array}$ & $\begin{array}{l}2 \mathrm{f} 983 \mathrm{~d} \\
73 \mathrm{f} 9 \mathrm{e} 3 \\
\text { f8e132 } \\
\text { aaf074 } \\
\mathrm{b} 8 \mathrm{~d} 4 \mathrm{~d} 1 \\
3 \mathrm{~b} 53 \mathrm{~d} 8 \\
8 \mathrm{a} 637 \mathrm{~b} \\
97 \mathrm{c} 2 \mathrm{c} 2 \\
871 \mathrm{~b} 9 \mathrm{~d} \\
\text { f969a0bf5f }\end{array}$ \\
\hline $\begin{array}{l}\text { "ABCD } \\
\text { EF } \\
\text { GHIJK } \\
\text { LM } \\
\text { NOPQR } \\
\text { ST } \\
\text { UVWX } \\
\text { YZ } \\
\text { abcdefg } \\
\text { hijklmn } \\
\text { opqrstu } \\
\text { vwxyz } \\
012345 \\
6 \\
789 " \\
\end{array}$ & $\begin{array}{l}\text { D174AB } \\
\text { 98 } \\
\text { D277D9 } \\
\text { F5 } \\
\text { A5611C2 } \\
\text { C } \\
\text { 9F419D9 } \\
\text { F }\end{array}$ & $\begin{array}{l}761 \mathrm{C} 457 \\
\text { B } \\
\text { F73B14D } \\
2 \\
7 \mathrm{E} 9 \mathrm{E} 926 \\
5 \\
\text { C46F4B4 } \\
\text { D } \\
\text { DA11F9 } \\
40\end{array}$ & $\begin{array}{l}\text { 7BFDB0B } \\
\text { B } \\
\text { AC222369 } \\
\text { 0B6659A2 } \\
\text { 61AF9C51 } \\
\text { A5B500A } \\
\text { D }\end{array}$ & $\begin{array}{l}\text { 2c8c3d } \\
\text { d50958 } \\
\text { f3d8f1 } \\
\text { d477c7 } \\
\text { b7eebf } \\
\text { ad8bae } \\
094 d c 9 \\
7691 b f \\
604 d f 5 \\
\text { a7693d21c } \\
\text { b }\end{array}$ \\
\hline & & & & \\
\hline
\end{tabular}

7. CONCLUSION AND FUTURE WORK

In this paper, we proposed a new message digest algorithm based on previous algorithms that can be used in any message integrity or signing applications. Most of cryptanalysis tries to find collision based on Differential attack but there is no way to find neutral bits for this kind of attack in parallel scheme. None of input messages that create same Hash Function in MD5 and SHA (collision) can create same output in our algorithm (even by changing bits with XOR, Addition or Multiplication techniques).

We can extend our algorithm to have a bigger size of hash $(512,768 \ldots)$ like SHAs by extending the block size of compression functions or increasing number of them. 
Table. 3 SHA-0 Collision Detected

\begin{tabular}{|c|c|c|c|}
\hline Message 1 & 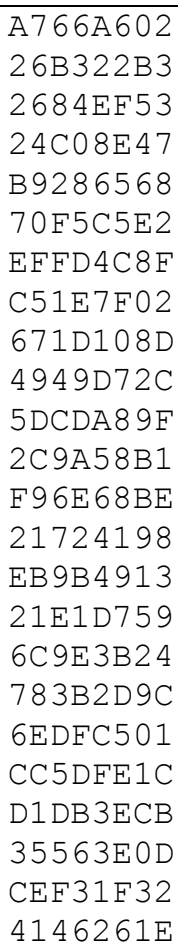 & $\begin{array}{l}\text { B65CFFE7 } \\
\text { D01B1A97 } \\
3 E 3 B 4 B 7 F \\
\text { E959B2BC } \\
247 \mathrm{D} 110 \mathrm{~F} \\
\mathrm{~B} 4590 \mathrm{CA} 3 \\
\mathrm{E} 68 \mathrm{DE} 835 \\
545410 \mathrm{D} 1 \\
\mathrm{~F} 5 \mathrm{~A} 4000 \mathrm{D} \\
\mathrm{D} 14 \mathrm{FBB} 3 \\
998 \mathrm{~F} 8755 \\
\mathrm{BDC} 38483 \\
\mathrm{BB} 0025 \mathrm{D} 2 \\
\mathrm{~F} 688 \mathrm{~B} 41 \mathrm{D} \\
\mathrm{FBE} 696 \mathrm{~B} 5 \\
1 \mathrm{~F} 89 \mathrm{DE} 84 \\
2879 \mathrm{D} 4 \mathrm{D} 8 \\
\mathrm{~A} 9935 \mathrm{EA} 5 \\
37 \mathrm{E} 69330 \\
14 \mathrm{C} 4 \mathrm{C} 68 \mathrm{~B} \\
24438 \mathrm{~A} 59 \\
8 \mathrm{BDF} 572 \mathrm{~F} \\
\text { DC9DBAA0 } \\
9994 \mathrm{BD} 5 \mathrm{C}\end{array}$ & $\begin{array}{l}73 \mathrm{BCF} 258 \\
53 \mathrm{FE} 3762 \\
3 \mathrm{~B} 519880 \\
\text { F55F52FE } \\
329 \mathrm{E} 603 \mathrm{C}\end{array}$ \\
\hline Message 2 & $\begin{array}{l}\text { A766A602 } \\
26 \mathrm{~B} 322 \mathrm{~B} 1 \\
2684 \mathrm{EF} 51 \\
\mathrm{~A} 4 \mathrm{C} 08 \mathrm{E} 45 \\
39286528 \\
70 \mathrm{~F} 55 \mathrm{E} 0 \\
6 \mathrm{FFD} 4 \mathrm{C} 8 \mathrm{D} \\
451 \mathrm{E} 7 \mathrm{~F} 02 \\
\mathrm{E} 71 \mathrm{D} 108 \mathrm{D} \\
4949 \mathrm{D} 72 \mathrm{C} \\
5 \mathrm{DCDA} 89 \mathrm{D} \\
\text { AC9A58B1 } \\
796 \mathrm{E} 68 \mathrm{FE} \\
\mathrm{A} 17241 \mathrm{D} 8 \\
6 \mathrm{~B} 9 \mathrm{~B} 4911 \\
\mathrm{~A} 1 \mathrm{E} 1 \mathrm{D} 719 \\
\mathrm{EC} 9 \mathrm{~EB} 26 \\
783 \mathrm{~B} 2 \mathrm{D} 9 \mathrm{E} \\
6 \mathrm{EDFC503} \\
4 \mathrm{C} 5 \mathrm{DFE} 5 \mathrm{C} \\
51 \mathrm{DB} 3 \mathrm{ECB} \\
35563 \mathrm{E} 0 \mathrm{D} \\
\text { CEF31F30 } \\
4146261 \mathrm{C}\end{array}$ & $\begin{array}{l}\text { B65CFFE7 } \\
\text { D01B1AD7 } \\
\text { BE3B4B } 7 \mathrm{~F} \\
\text { E959B2FC } \\
\text { A47D110D } \\
34590 \mathrm{CE} 3 \\
668 \mathrm{DE} 875 \\
\mathrm{D} 45410 \mathrm{D} 1 \\
\mathrm{~F} 5 \mathrm{~A} 4000 \mathrm{D} \\
\mathrm{D} 14 \mathrm{FBB} 01 \\
198 \mathrm{~F} 8755 \\
3 \mathrm{DC} 38481 \\
\mathrm{BB} 0025 \mathrm{D} 0 \\
7688 \mathrm{~B} 41 \mathrm{~F} \\
7 \mathrm{BE} 696 \mathrm{~F} 5 \\
9 \mathrm{~F} 89 \mathrm{DE} 86 \\
\mathrm{~A} 879 \mathrm{D} 498 \\
29935 \mathrm{EA} 7 \\
37 \mathrm{E} 69330 \\
14 \mathrm{C} 4 \mathrm{C} 689 \\
\mathrm{~A} 4438 \mathrm{~A} 59 \\
8 \mathrm{BDF} 572 \mathrm{~F} \\
\mathrm{DC} 9 \mathrm{DBAE} 0 \\
1994 \mathrm{BD} 5 \mathrm{C}\end{array}$ & $\begin{array}{l}73 \mathrm{BCF} 258 \\
\mathrm{D} 3 \mathrm{FE} 3762 \\
3 \mathrm{~B} 519880 \\
755 \mathrm{~F} 52 \mathrm{FC} \\
329 \mathrm{E} 603 \mathrm{E} \\
\mathrm{CF} 20 \mathrm{~A} 439 \\
45 \mathrm{CF} 3 \mathrm{~A} 69 \\
5 \mathrm{E} 4771 \mathrm{C} 5 \\
52 \mathrm{~B} 69 \mathrm{EDD} \\
\mathrm{C} 57 \mathrm{AB} 399 \\
57 \mathrm{E} 8613 \mathrm{C} \\
\mathrm{A} 6 \mathrm{~A} 72980 \\
3 \mathrm{E} 976010 \\
209 \mathrm{~B} 5 \mathrm{DB} 4 \\
77 \mathrm{~B} 53065 \\
50758 \mathrm{E} 3 \mathrm{D}\end{array}$ \\
\hline $\begin{array}{l}\text { Hash } \\
\text { Output }\end{array}$ & $\begin{array}{l}\text { C9F16077 } \\
8 \mathrm{~B} 7 \mathrm{E} 20 \mathrm{C} 2\end{array}$ & $\begin{array}{l}7 \mathrm{D} 4086 \mathrm{FE} \\
28 \mathrm{~A} 4006 \mathrm{~B}\end{array}$ & 8095 FBA5 \\
\hline
\end{tabular}

\section{REFERENCE}

[1]. S.Vaudenay "A Classical Introduction to Cryptography Applications for Communications Security" Springer, 2006, P 74.

[2] R. Rivest. The MD5 Message-Digest Algorithm [rfc1321]

[3]. NIST, "Secure Hash Standard," FIPS PUB 180, May. 1993.

[4]. F. Chabaud, A. Joux. "Differential Collisions in SHA-0". In Advances in Cryptology CRYPTO'98, Santa Barbara, CA, Lecture Notes in Computer Science 1462. SpringerVerlag, NY, pp. 56-71, 1998.

[5]. E. Biham, R. Chen, A. Joux, P. Carribault, W. Jalby and C. Lemuet. "Collisions in SHA-0 and Reduced SHA-1In Advances in Cryptology" - Eurocrypt'05, SpringerVerlag, 2005

[6]. NIST FIPS PUB 180-1. Oct.2001.

[7]. NIST, "Secure Hash Standard (SHS)", FIPS PUB 180-2, 2002.

[8]. S. Chang, M. Dworkin, Workshop Report, The First Cryptographic Hash Workshop, Report prepared, NIST 2005.

[9]. E. Biham, R. Chen, "New results on SHA-0 and SHA-1" Crypto 2004 Rump Session, Aug. 2004.

[10]. K. Matusiewicz and J. Pieprzyk "Finding good differential patterns for attacks on SHA-1" eprint 2004 Available : http://eprint.iacr.org/2004/364.pdf.

[10]. F. Chabaud, A. Joux. "Differential Collisions in SHA0". In Advances in Cryptology CRYPTO'98, Santa Barbara, CA, Lecture Notes in Computer Science 1462. Springer-Verlag, NY, pp. 56-71, 1998.

[11] Rivest $\mathrm{R}$ L. The MD5 message digest algorithm $[\mathrm{EB} / \mathrm{OL}]$.

[12]Xiaoyun Wang, Dengguo, k., m., m, HAVAL-128 and RIPEMD], Cryptology ePrint Archive Report 2004/199, 16 August 2004,

[13] J. Black, M. Cochran, T. Highland: A Study of the MD5 Attacks: Insights and Improvements, March 3, 2006

[14]Tao Xie and DengguoFeng (30 May 2009). How to Find Weak Input Differences for MD5 Collision Attacks.

[15]ChristofPaar, Jan Pelzl, Bart Preneel (2010). Understanding Cryptography: A Textbook for Students and ractitioners.Springer.p. 7. ISBN 3642041000.

[16]M.E. Hellman, H.R. Amirazizi, "A Cryptanalytic Time Memory Trade-Off," IEEE Transactions on Information Theory, vol. 34-3, pp. 505-512, 1988

[17]. X. Wang, X. D. Feng, X. Lai and H. Yu., "Collisions for Hash Functions MD4, MD5, HAVAL-128 and RIPEMD," Cryptology ePrint Archive: Report 2004/199, Aug. 2004 http://eprint.iacr.org/2004/199/ 